\title{
The role of thiamine in schizophrenia
}

\author{
Khanh vinh quốc Lương ${ }^{*}$, Lan Thi Hoàng Nguyễn \\ Vietnamese American Medical Research Foundation, Westminster, California, U.S.A
}

Email address:

Lng2687765@aol.com (K. v. q. Lương)

\section{To cite this article:}

Khanh vinh quốc Lương, Lan Thi Hoàng Nguyễn. The Role of Thiamine in Schizophrenia. American Journal of Psychiatry and Neuroscience. Vol. 1, No. 3, 2013, pp. 38-46. doi: 10.11648/j.ajpn.20130103.11

\begin{abstract}
Objective: Review the relationship between thiamine and schizophrenia. Methods: Information was obtained from MEDLINE. Results: Nutritional status has been related to the development of schizophrenia. Genetic studies have identified numerous factors that link thiamine to schizophrenia, including the renin angiotensin system, heme oxygenase-1, advanced glycation end products, alpha-antitrypsin, coenzyme Q10, glycogen synthetase kinase-3, and the transcription factor $\mathrm{p} 53$. Thiamine has also been implicated in schizophrenia via its effects on matrix metalloproteinases, the Wnt $\beta$ catenin signaling pathway, the mitogen-activated protein kinase pathways, the reduced form of nicotinamide adenine dinucleotide phosphate, prostaglandins, cyclooxygenase-2, reactive oxidative stress, and nitric oxide synthase. Conclusions: These data suggest a role of thiamine in patients with schizophrenia. Therefore, additional investigation of thiamine in schizophrenic patients is required.
\end{abstract}

Keywords: Thiamine, Schizophrenia, Transketolase, Vitamin B1

\section{Introduction}

Schizophrenia is devastating mental illness that is characterized by symptoms of disruptions in reality, such as hallucinations and delusions. Nutritional status has been related to the development of schizophrenia. Poor performance IQ mediates the relationship between poor nutrition at age 3 and interpersonal and schizotypal personality at age 23 [1]. Early environmental events may be relevant in the etiology of schizophrenia. An association between prenatal starvation and schizophrenia has been observed in Dutch and Chinese famines [2-4].The developing brain is vulnerable to reduced thiamine intake and that the period of vulnerability may be different for activity and avoidance learning [5]. These authors observed that rat pups that suckle from thiamine-deficient (TD) dams exhibited memory deficits. Thiamine deficiency degrades the link between spatial behavior and hippocampal synapsin I and phosphorylated synapsin I protein levels. These proteins regulateneuro-transmitter release, which has implicated in hippocampal-dependent learning [6]. The mammillary bodies (MBs) are important relay nuclei with limbic and extra-limbic connections. MBs play important roles in memory formation, and these nuclei are affected during thiamine deficiency [7]. MB abnormalities are observed in patients with schizophrenia [8-9]. The number of parvalbumin-immuno-reactive $\mathrm{MB}$ neurons is reduced by more than $50 \%$ in the postmortem brains of schizophrenics compared to matched control brains [9]. Acute sulbutiamine injection increased thiamine triphosphate (TTP) in rat tissues [10] and induced a modulatory effect on glutamatergic and dopaminergic cortical transmissions in the rat brain [11]. Severe thiamine deficiencies, such as Wernicke encephalopathy and Beriberi heart disease, are observed in patients with schizophrenia [12-15]. Gontzeaet al. [16] assessed the thiamine status of patients with neurosis in a psychiatric department and observed a decreased in thiamine excretion and erythrocyte transketolase activity in neurotic patients compared to healthy control participants. These observations suggest the presence of thiamine deficiencies in these psychiatric patients. Erythrocyte transketolase abnormalities are also observed in schizophrenic patients [17-18]. Benton et al. [19] observed a significant association between improved thiamine status and enhanced performance across a range of cognitive-function tests in women in a controlled trial. These authors observed significant cognitive deteriorations in the psychoneurotic scales of the Minnesota Multiphasic Personality Inventory (MMPI) in thiamine deprived participants. However, thiamine supplementation reverses these effects [20], and thiamine supplementation improves the symptoms of neurotic patients [21]. Mice treated with thiamine tetrahydrofurfuryl disulfide (TTFD) exhibit decreased locomotor activity in solitary open-field testing. 
TTFD-treated mice engage in more passive cuddling-type behaviors than vigorous play-type behaviors and exhibit a diminished startle response to loud noises [22]. Sacks et al. [23] demonstrated that a combination of acetazolamine and thiamine improved clinical presentation by reducing or eliminating hallucinations, delusions, and bizarre behaviors in most schizophrenic patients. Acetazolamide alone produced little benefit in one schizophrenic patient, but acetazolamine treatment in combination with thiamine in the same patient produced significant clinical improvement. A TD female patient developed auditory hallucinations, persecution delusion, catatonic stupor, and catalepsy. Her psychosis was ameliorated by repetitive intravenous thiamine administrations [24]. These results suggest a relationship between thiamine and schizophrenia. Therefore, we review the role of thiamine in schizophrenia in the present paper.

\section{The Genomic Factors Associated with Thiamine in the Development of Schizophrenia}

Genetic studies provide an excellent opportunity to associate molecular variations with epidemiological data. DNA sequence variations such as polymorphisms exert modest and subtle biological effects.

The primary function of the renin angiotensin system (RAS) is to maintain fluid homeostasis and regulate blood pressure. Several components of the RAS and its receptors are expressed in the central nervous system (CNS) [25-28], suggesting the important of RAS in the brain. Prepulse inhibition (PPI) is a measure of sensori-motor gating, which is disrupted in patients with schizophrenia (PPI) [29]. Angiotensin-converting enzyme (ACE) interacts with dopaminergic mechanisms in the brain to modulate PPI in mice [30]. Cerebrospinal fluid (CSF) ACE is significantly correlated with the length of schizophrenic psychosis [31]. Elevated CSF ACE and plasma renin activity are observed during antipsychotic drug treatment in schizophrenic patients [32-33]. Genotype distribution is significantly different in males with schizophrenia compared to male controls. The frequencies of the $D D$ genotype and $D$ allele are higher than those of the $I I$ genotype and $I$ allele in schizophrenic males [34]. A modest association between $A C E$ polymorphism and polydipsia has been demonstrated for schizophrenic patients [35]. An interaction between thiamine and the RAS has been observed. Thiamine deficiency significantly depresses plasma and urinary aldosterone responses to sodium deprivation in rats [36]. Thiamine attenuates hypertension and metabolic abnormalities in spontaneous hypertensive rats (SHRs). Thiamine repletion down-regulates the expression of angiotensinogen $(-80 \%)$, ACE $(-77 \%)$, and angiotensin type 1 receptor $(-72 \%)$ mRNA transcripts in SHRs [37]. These observations suggest an effect of thiamine on ACE activity in schizophrenia.
Heme oxygenase-1 (HO-1) is a stress protein that may confer cytoprotection by enhancing the catabolism of prooxidant hemeby the radical-scavenging bile pigments biliverdin and bilirubin. The HO-1 gene is up-regulated by a host of noxious stimuli and is induced in CNS tissues that are affected by neurological diseases [38]. Basal HO-1 expression is low in the normal brain and is restricted to small groups of scattered neurons and neuroglia [39]. Schizophrenic-like features are observed in transgenic mice that overexpress human HO-1 in the astrocytic compartment [40]. Similarly, thiamine deficiency produces region-specific neuronal loss and $\mathrm{HO}-1$ induction in microglia [41-42]. Thiamine administration inhibits further neuronal loss and the induction of HO-1-positive microglia, but other microglial changes persist [43].

The p53 gene and protein play critical roles in the regulation of the normal cell cycle, cell cycle arrest, and apoptosis. The p53 protein is to serve as a critical regulator of neuronal apoptosis in the CNS [44]. The p53 gene is a candidate susceptibility gene in schizophrenia [45]. Significant associations between the p53 gene and schizophrenia are observed in case-control and familybased samples [46]. Polymorphisms in p53 are observed schizophrenic patients [47-49]. P53 variants contribute to abnormal metabolic activity and white matter in the frontal lobe of schizophrenic patients [50]. By contrast, an increased number of thiamine transporters are observed in cells that over-express thiamine transport genes (mTHTR-1) and in cells that are exposed to conditions that induce DNA damage or p53 activation [51]. Thiamine diphosphate (TDP) inhibits p53 binding, and thiamine inhibits intracellular p53 activity [52]. Thiamine treatment significantly decreases p53 expression in cultured retinal neurons from diabetic rats [53]. These observations suggest that the transcription factor p53 is activated in schizophrenia with an increasing apoptotic response from cellular damage and that thiamine ameliorates these effects on cells.

Alpha-1 antitrypsin (ATT) is the most abundant circulating serine protease inhibitor. The ATT activity is enhanced in patients with schizophrenia [54-57]. A significant difference in phenotype and gene frequencies is observed between schizophrenic patients with and without a family history of schizophrenia. A significant increase in the M1 gene and a decrease in M2 gene are observed in patients with a family history of schizophrenia [58]. The ATT polymorphism with a non-MM genotype significantly increased the incidence of thiamine deficiency [59].

Coenzyme Q10 (CoQ10 or ubiquinone) is an electron carrier of the mitochondrial respiratory chain with antioxidant properties. The erythrocyte levels of CoQ10 were low in patients with schizophrenia [60]. In the TD liver, the concentration of ubiquinone is nearly doubled and a thiamine supplement promptly decreases levels to that of controls [61].

Glycogen synthetase kinase-3(GSK3) is a protein kinase that is involved in many physiological processes (e.g., metabolism, gene expression and apoptosis). Dysfunction 
of protein kinase FA/GSK-3 $\alpha$ was reported in lymphocytes of patients with schizophrenic disorder [62]. Hippocampal GSK- $3 \alpha$ and GSK-3 $\beta$ mRNA levels were significantly lower (22\% and $28 \%$, respectively) in the tissue from the schizophrenic patients compared with the normal controls [63]. A significant reduction in CSF GSK-3 $\beta$ protein levels was reported in schizophrenic patients compared to healthy subjects [64]. GSK-3 $\beta$ protein levels were also reduced in the frontal cortex of rats with the neonatal excitotoxic hippocampal lesion used as a model of schizophrenia and in schizophrenic patients [65-67]. Exposure to pyrithiamine, an anti-thiamine compound, also increases the $\beta$-amyloid protein accumulation and GSK3 activity in the brain [68]. Benfotiamine improved cognitive function, reduced amyloid deposition, and suppressed GSK3 activity in an animal model of Alzheimer's disease [69]. These findings suggest that thiamine may influence schizophrenia by suppressing GSK3 activity.

Glyoxalase 1 (Glyo-1) catalyzes the first and ratelimiting step of methylglyoxal (MG) removal, which is the major precursor of advanced glycation end product (AGE) formation. AGE is a heterogeneous group of macromolecules formed by the non-enzymatic glycation of proteins, lipids and nucleic acids. RAGEs are multi-ligand receptors; their ligands are also likely to recognize several receptors in mediating their biological effects [70]. Arai et al. [71] isolated DNA from peripheral blood and postmortem brain tissue of schizophrenic patients, they detected genetic and function alterations in Glyo-1 that associated with marked reductions in enzyme activity. Genetic abnormalities in Glyo-1 are associated with patients with schizophrenia [72-74]. Soluble RAGEs were elevated in patients with schizophrenia [75]. RAGE gene polymorphism is associated with schizophrenia [76]. Thiamine and a benfotiamine supplement prevented tissue accumulation and increased the urinary excretion of protein glycation, oxidation and nitration adducts associated with experimental diabetes [77]. Karachalias et al. [78] reported that the hydroimidazolone of AGE residues derived from glyoxal and methylglyoxal (G-H1 and MG-H1, respectively) increased by $115 \%$ and $68 \%$, respectively, in streptozotocin-induced (STZ) diabetic rats, and thiamine and benfotiamine normalized these residues. However, Ncarboxymethyl-lysine (CML) and N-carboxyethyl-lysine (CEL) residues increased by $74 \%$ and $118 \%$, respectively, in diabetic-induced rats, and only thiamine normalized these residues. Serum markers of endothelial dysfunction, oxidative stress, and AGE increased after a meal high in AGE content. Benfotiamine significantly reduced these effects [79]. The addition of benfotiamine enhanced transketolase activity and decreased the expression of AGE and RAGE in a peritoneal dialysis model of uremic rats [80]. The combined administration of thiamine and vitamin B6 to patients with diabetic nephropathy decreased DNA glycation in leukocytes; however, vitamin B6 alone did not have such an effect [81].

\section{The Non-Genomic Role of Thiamine in Schizophrenia}

Matrix metalloproteinases (MMPs) are proteolytic enzymes that are responsible for extracellular matrix remodeling and the regulation of leukocyte migration through the extracellular matrix, which is an important factor involved in inflammatory processes and infectious diseases. MMPs are produced by many cell types including lymphocytes, granulocytes, astrocytes and activated macrophages. A high frequency of positive-MMP-9 activity was detected in serum in patients with schizophrenia [82]. Autoantibodies from schizophrenia patients induce MMP-3 production in the rat frontal cortex [83]. A significant functional MMP-9 polymorphism has been observed in schizophrenic patients compared to healthy controls [84]. MMP-9 is also up-regulated in the TD mouse brain [41-42]. Studies were performed in vulnerable (medial thalamus) versus spared (frontal cortex) regions of the brain. The hemorrhagic lesions and a concomitant loss in protein expression of occluding, such as zonaoccludens, were observed in the medial thalamus of TD- mice. MMP-9 levels were also selective increased in the medial thalamus of these animals, and were found to be localized in the vascular endothelium, as well as in PMNCs [85]. Thiamine prevents diabetes-induced cardiac fibrosis and decreases MMP-2 activity in the hearts of diabetic rats [86]. Thiamine and benfotiamine correct the increases in MMP-2 activity that result from high glucose levels in human retinal pericytes and increase TIMP-1 [87]. Fursutiamine, a vitamin B1 derivative, enhances the chondroprotective effects of glucosamine hydrochloride and chondroitin sulfate and reduces the level of MMP-1 in rabbit experimental osteoarthritis [88].

The mitogen-activated protein kinase (MAPK) pathways provides a key link between the membrane-bound receptors that receive these cues and changes in the pattern of gene expression, including the extracellular signal-regulated kinase (ERK) cascade, the stress-activated protein kinases/c-jun N-terminal kinase (SAPK/JNK) cascade, and the p38 MAPK/RK/HOG cascade [89]. MAPK levels are elevated in the cerebellar vermis of postmortem schizophrenic subjects compared to normal subjects [90]. Benfotiamine modulates the macrophage response to bacterial endotoxin-induced inflammation by preventing the activation of p-38 MAPK and stress-activated kinases (SAPK/JNK) [91].

The reduced form of the nicotinamide adenine dinucleotide phosphate (NADPH) oxidase (NOX) enzyme complex mediates critical physiological and pathological processes including cell signaling, inflammation and mitogenesis, via the generation of reactive oxygen species (ROS) from molecular oxygen. NOX is widely expressed in various immune cells, such as microglia, macrophages, and neutrophils. The dorsolateral prefrontal cortex of schizophrenic patients exhibits a significant decrease in NADPH-expressing neurons in the superficial white matter 
and the overlying cortex. However, a significant increase in NADPH-expressing neurons is observed in white matter below the cortex. [92].Distorted distribution of NADPHneurons was also found in the lateral temporal lobe [93]. NADPH levels in mediodorsal thalamus of postmortem schizophrenic patients are reduced compared to controls [94]. The NADPH quinine oxidoreductase 1 (NQO1) gene polymorphism $(609 \mathrm{C} / \mathrm{T})$ increases the susceptibility to the development of tardive dyskinesia in schizophrenia, but this polymorphism is not associated with the development of schizophrenia in the Korean population [95]. Behrens and Sejnowski [96] suggest that the persistent activation of the IL-6/Nox2 pathway is an environmental factor that tips the redox balance toward schizophrenic symptoms during late adolescence and early adulthood in individuals with genetic predisposition. Thiamine is an essential coenzyme for transketolase, which is part of the pentose phosphate pathway that maintains cellular NADPH levels. Thiamine is cytoprotective and restores NADPH levels, glyoxal detoxification and mitochondrial membrane potential in hepatocytes with glyoxal toxicity [97]. NADPH cytochrome c-reductase levels are increased in TD animals [98]. Benfotiamine treatment under normo- and hyperglycemic conditions significantly down-regulates Nox4 expression [99]. Animals that are fed a high-thiamine diet exhibit approximately $57 \%$ of the NADPH-cytochrome c reductase activity of animals that are fed a TD diet [100]. The data suggest a role for thiamine in, protecting schizophreniavia the regulation of NADPH-cytochrome $\mathrm{c}$ activity.

Prostaglandins (PGs) participate in inflammatory processes. Cyclooxygenase(COX) convertsarachidonic acid into PGs. These released prostanoids play an important role in normal neural function, including spatial learning, synaptic plasticity and long-term potentiation [101]. Autoantibodies from schizophrenic patients induce $\mathrm{PGE}_{2}$ production in the rat frontal cortex [83]. Schizophrenic patients exhibit higher plasma levels of pro-inflammatory $\mathrm{PGE}_{2}$ than age-matched controls [102]. COX-1 and prostaglandin-endoperoxide receptor 3 (PTGER3) mRNA expression are increased in older schizophrenic patients $(>$ 40 years of age) compared to matched controls and younger schizophrenic patients $(<40$ years of age) [103]. A prospective double-blind study revealed that $\mathrm{COX}-2$ inhibitor add-on therapy produces significantly greater improvements in Positive and Negative Syndrome Scale (PANSS) scores and all subscales during the acute phase compared torisperidone therapy alone in schizophrenic patients [104-105]. A significantly better outcome was observed in early stage schizophrenic patients who were treated with amisulpride plus celecoxib compared patients who received amisulpride plus placebo [106]. Moreover, the expressions of COX-2 mRNA and $\mathrm{PGE}_{2}$ are selectively increased in vulnerable regions during the symptomatic stages of TD encephalopathy in animal models [107]. Upregulation of 15-hydroxyprostaglandin dehydrogenase (15PGDH) expression was observed in breast cancer cell lines transfected with thiamine transporter (THTR2) gene and down-regulation was observed after suppression of THTR2 with siRNA vectors [108]. Over-expressed of 15-PGDH inhibited IL-1 $\beta$-induced COX-2 expression [109]. Benfotiamine inhibits the expression of COX-2 in endotoxininduced uveitis in rats [110]. Benfotiamine also blocks the expression of COX-2 and its $\mathrm{PGE}_{2}$ product in murine macrophages in a LPS-induced cytotoxicity model [91].

Reactive oxygen species (ROS) play a major role in various cell-signaling pathways. ROS activates various transcription factors and increases the expression of proteins that control cellular transformation, tumor cell survival, tumor cell proliferation and invasion, angiogenesis, and metastasis. Altered antioxidant enzymes and oxidative stress are associated with schizophrenic patients. Increased levels of lipid peroxidation in plasma, red blood cells (RBCs), and cerebrospinal fluid are reported in schizophrenic patients [111-114]. Elevated plasma superoxide dismutase (SOD) activities are observed in first-episode and drug naïve schizophrenic patients compared to controls [115]. Serum SOD activity is also significantly increased in schizophrenic patients compared to controls [116]. An association between polymorphismsin the manganese-containing SOD (Mn-SOD) gene and schizophrenia has been observed [117], suggesting that an Mn-SOD variant contributes to the physiopathogenesis of schizophrenia. A significant increase in malondialdehyde (MDA) levels has been observed in schizophrenic patients, compared to age-matched control group [118]. Similarly, oxidative stress is associated with region-specific neuronal death, and lipid peroxidation products accumulate in the remaining thalamic neurons after 11 days in TD animal models [119].Cardiac oxidative stress is involved in TD-induced heart failure rats; Intracellular cardiac superoxide, SOD protein, and $\mathrm{H}_{2} \mathrm{O}_{2}$ contents are increased while GSH peroxidase activity is decreased [120]. Thiamine inhibits lipid peroxidation and the free radical oxidation of oleic acid in rat liver microsomes in vitro [121]. In one study, male Wistar rats were intoxicated with a dose of ethanol; the levels of MDA, reduced glutathione and vitamin $\mathrm{E}$ were measured as parameters of the antioxidant system of the liver and were improved in the thiaminetreated group [122].Thiamine supplement suppressesparaquat -induced Mn-SOD and glucose-6phosphate dehydrogenase in vitro [123].

Nitric oxide synthase (NOS) synthesizes nitric oxide (NO), which regulates a variety of important physiological responses, including cell migration, the immune response, and apoptosis.NO affects the development and function of the CNS. NO enhances dopamine release in the striatum in animal models [124]. Extracellular dopamine release increases following the intra-striatal infusion of NOS substrates [125]. NOS concentrations are increased in the cerebellar vermis in postmortem brain tissue of schizophrenic patients compared to controls [126]. NOS variants are associated with schizophrenia [127-129]. Auto antibodies from schizophrenia patients induce NO production in the rat frontal cortex [83]. A remarkable 
increase in RBC NO levels is observed in schizophrenic patients compared to control subjects [130]. Reduced plasma levels of glutathione (GSH) are significantly lower in schizophrenic patients compared to controls [131]. Glutathione deficiency during postnatal development reduces parvalbumin expression in a subclass of $\gamma$-amino butyric acid (GABA) neurons in the anterior cingulate cortex in an animal model of schizophrenia [132]. GSH Stransferase polymorphisms are a risk factor for schizophrenia [133]. Endothelial NOS gene deletion restores blood brain barrier integrity and attenuates neurodegeneration in the TD mouse brain [42]. Benfotiamine inhibits iNOS expression in endotoxininduced uveitis in rats [107]. Benfotiamine also inhibits iNOS expression in an LPS-induced cytotoxicity model in murine macrophages [91]. Thiamine improves reduced GSH levels in acutely alcoholic rats [122].

\section{Conclusions}

In the present paper, the relationship between thiamine and schizophrenia is reviewed. Genetic studies provide opportunities to determine which proteins link thiamine to a schizophrenic pathology. The effects of thiamine are mediated by numerous non-genomic mechanisms, including effects on protein expression, oxidative stress, inflammation, and cellular metabolism. However, thiamine absorption decreases with advancing age [134]. Patients in the early stages of thiamine-deficient encephalopathy (Wernicke's encephalopathy) rapidly respond to large doses of parental thiamine. The initial doses of thiamine are generally $100 \mathrm{mg}$ two to three times daily for 1 to 2 weeks. Therefore, further investigations of thiamine in schizophrenic patients are required, and a cautious approach is advisable before recommending the widespread use of thiamine in schizophrenic patients.

\section{Acknowledgment}

Conflict of interest statement: The authors, Dr. Khanh Luong and Dr. Lan Nguyen, report no competing interests. Ethical approval: Not required

Funding: The authors, Dr. Khanh Luong and Dr. Lan Nguyen, received no funding for this study.

\section{References:}

[1] Venables PH, Raine A. Poor nutrition at age 3 and schizotypal personality at age 23 : the mediating role of age 11 cognitive functioning.Am J Psychiatry. 2012; 169:822-30.

[2] Susser E, Neugebauer R, Hoek HW, Brown AS, Lin S, et al. Schizophrenia after prenatal famine. Further evidence.Arch Gen Psychiatry. 1996; 53:25-31.

[3] Hoek HW, Brown AS, Susser E. The Dutch famine and schizophrenia spectrum disorders.Soc Psychiatry PsychiatrEpidemiol. 1998; 33:373-9.
[4] St Clair D, Xu M, Wang P, Yu Y, Fang Y, et al. Rates of adult schizophrenia following prenatal exposure to the Chinese famine of 1959-1961.JAMA. 2005;294:557-62.

[5] Bell JM, Stewart CN. Effects of fetal and early postnatal thiamin deficiency on avoidance learning in rats. J Nutr. $1979 ; 109: 1577-83$.

[6] Resende LS, Ribeiro AM, Werner D, Hall JM, Savage LM. Thiamine deficiency degrades the link between spatial behavior and hippocampal synapsin I and phosphorylated synapsin I protein levels. Behav Brain Res. 2012;232:421-5.

[7] Gupta RK, Yadav SK, Saraswat VA, Rangan M, Srivastava A, et al. Thiamine deficiency related microstructural brain changes in acute and acute-on-chronic liver failure of nonalcoholic etiology. ClinNutr. 2012; 31:422-8.

[8] Briess D, Cotter D, Doshi R, Everall I. Mamillary body abnormalities in schizophrenia.Lancet. 1998; 352:789-90.

[9] Bernstein HG, Krause S, Krell D, Dobrowolny H, Wolter M, et al. Strongly reduced number of parvalbuminimmunoreactive projection neurons in the mammillary bodies in schizophrenia: further evidence for limbic neuropathology. Ann N Y Acad Sci. 2007; 1096:120-7.

[10] Bettendorff L, Weekers L, Wins P, Schoffeniels E. Injection of sulbutiamine induces an increase in thiamine triphosphate in rat tissues. BiochemPharmacol. 1990; 40:2557-60.

[11] Trovero F, Gobbi M, Weil-Fuggaza J, Besson MJ, Brochet D, Pirot S. Evidence for a modulatory effect of sulbutiamine on glutamatergic and dopaminergic cortical transmissions in the rat brain. NeurosciLett. 2000;292:49-53.

[12] Harrison RA, Vu T, Hunter AJ. Wernicke's encephalopathy in a patient with schizophrenia.J Gen Intern Med. 2006;21:C8-C11.

[13] Salawu F, Kwajaffa S. Wernicke's encephalopathy in a Nigerian with schizophrenia.Ann Afr Med. 2007;6:200-2.

[14] Tsai HY, LiehYeh T, Sheei-Meei W, Chen PS, Yang YK. Starvation-induced Wernicke's encephalopathy in schizophrenia.Psychiatry ClinNeurosci. 2004;58:338-9

[15] Danielson C, Joyce SM. Beriberi heart disease in a schizophrenic with an unusual diet.J Emerg Med. 1990; 8:705-7.

[16] Gontzea IG, Gorcea V, Popescu F. Biochemichal Assessment of Thiamin Status in Patients with Neurosis. NutrMetab. 1975; 19:153-7.

[17] Casanova M F, Diamond B I, Pathiraja A P, Nguyen T H. Erythrocyte transketolase abnormalities in patients with schizophrenia. Society for Neuroscience Abstracts. 1992;18(Iss.1-2):571

[18] Carney MW, Williams DG, Sheffield BF. Thiamine and pyridoxine lack newly-admitted psychiatric patients.Br J Psychiatry. 1979; 135:249-54.

[19] Benton D, Fordy F, Haller J. The Impact of Long-Term Vitamin Supplementation on Cognitive Functioning. Psychopharm. 1995; 117:298-305.

[20] Brozek J, Caster WO. Psychologic Effects of Thiamine Restriction and Deprivation in Normal Young Men. Am J ClinNutr. 1957; 5:109-20. 
[21] Lonsdale D, Shamberger RJ. Red cell transketolase as an indicator of nutritional deficiency. Am J ClinNutr. 1980; 33:205-11.

[22] Hills JI, Golub MS, Bettendorff L, Keen CL. The effect of thiamin tetrahydrofurfuryl disulfide on behavior of juvenile DBA/2J mice. NeurotoxicolTeratol. 2012; 34:242-52.

[23] Sacks W, Esser AH, Feitel B, Abbott K. Acetazolamide and thiamine: an ancillary therapy for chronic mental illness.Psychiatry Res. 1989; 28:279-88.

[24] Sasaki T, Yukizane T, Atsuta H, Ishikawa H, Yoshiike T, et al. [A case of thiamine deficiency with psychotic symptoms-blood concentration of thiamine and response to therapy]. SeishinShinkeigakuZasshi. 2010; 112:97-110. [Article in Japanese]

[25] Changaris DG, Keil LC, Severs WB. Angiotensin II immunohistochemistry of the rat brain. Neuroendocrinol. $1978 ; 25: 257-74$.

[26] Healy DP, Printz MP. Distribution of immunoreactive angiotensin II, angiotensin I, angiotensinogen, and renin in the central nervous system of intact and nephrectomized rats. Hypertension. 1984;6(suppl 1):130-6.

[27] Ganten D, Hermann K, Bayer D, Unger T, Lang RR. Angiotensin synthesis in the brain and increased turnover in hypertensive rats. Science. 1983; 221:869-71.

[28] Dzau VJ, Ingelfinger J, Pratt RE, Ellison KE. Identification of renin and angiotensinogen messenger RNA sequences in rat brain. Hypertension. 1986; 8:544-8.

[29] Braff DL, Geyer MA. Sensorimotor gating and schizophrenia. Human and animal model studies.Arch Gen Psychiatry. 1990; 47:181-8.

[30] Van den Buuse M, Zheng TW, Walker LL, Denton DA. Angiotensin-converting enzyme (ACE) interacts with dopaminergic mechanisms in the brain to modulate prepulse inhibition in mice.NeurosciLett. 2005; 380:6-11.

[31] Wahlbeck K, Ahokas A, Nikkilä H, Miettinen K, Rimón R. Cerebrospinal fluid angiotensin-converting enzyme (ACE) correlates with length of illness in schizophrenia.Schizophr Res. 2000; 41:335-40.

[32] Wahlbeck K, Rimón R, Fyhrquist F. Elevated angiotensinconverting enzyme (kininase II) in the cerebrospinal fluid of neuroleptic-treated schizophrenic patients.Schizophr Res. 1993; 9:77-82.

[33] Robertson D, Michelakis AM. The effect of chlorpromazine on plasma renin activity and aldosterone in man.J ClinEndocrinolMetab. 1975; 41:1166-8.

[34] Golimbet VE, Andreev TV, Abramova LI, Kaleda VG. Insertion-deletion polymorphism of angiotensin-1-converting enzyme gene in patients with endogenic psychoses].NeurosciLett. 2005; 380:6-11. [Article in Russian]

[35] Ouyang WC, Wang YC, Hong CJ, Cheng CY, Tsai SJ. Association study of angiotensin-converting enzyme gene polymorphism with schizophrenia and polydipsia.Neuropsychobiology. 2001; 44:31-5.

[36] Hastings MM, Van JL. Sodium deprivation during thiamin deficiency in rats: hormonal, histological, and behavioral responses. J Nutr. 1981; 111:1955-63.
[37] Tanaka T, Sohmiya K, Kono T, Terasaki F, Horie R, et al. Thiamine attenuates the hypertension and metabolic abnormalities in CD36-defective SHR: uncoupling of glucose oxidation from cellular entry accompanied with enhanced protein O-GlcNAcylation in CD36 deficiency.Mol Cell Biochem. 2007; 299:23-35.

[38] Hascalovici JR, Vaya J, Khatib S, Holcroft CA, Zukor H, et al. Brain sterol dys-regulation in sporadic $\mathrm{AD}$ and MCI: Relationship to heme oxygenase-1. J Neurochem. 2009; $110: 1241-53$

[39] Baranano DE, Snyder SH. Neural roles for hemeoxygenase: contrasts to nitric oxide synthase. Proc. Natl. Acad. Sci. USA. 2001; 98:10996-1002.

[40] Song W, Zukor H, Lin SH, Hascalovici J, Liberman A, et al. Schizophrenia-Like Features in Transgenic Mice Over expressing Human HO-1 in the Astrocytic Compartment. J Neurosci. 2012; 32:10841-53.

[41] Calingasan NY, Gibson GE. Dietary restriction attenuates the neuronal loss, induction of heme oxygenase-1 and blood-brain barrier breakdown induced by impaired oxidative merabolism. Brain Res. 2000; 885:62-9.

[42] Beauchesne É, Desjardins P, Hazell AS, Butterworth RF. eNOS gene deletion restores blood-brain barrier integrity and attenuates neurodegeneration in the thiamine-deficient mouse brain. J Neurochem. 2009; 111:452-9.

[43] Ke ZJ, DeGiorgio LA, Volpe BT, Gibson GE. Reversal of thiamine deficiency-induced neurodegeneration. J NeuropatholExp Neurol. 2003; 62:195-207.

[44] Araki N, Morimasa T, Sakai T, Tokuoh H, Yunoue S, et al. Comparative analysis of brain proteins from p53-deficient mice by two-dimensional electrophoresis. Electrophoresis. $2000 ; 21: 1880-9$

[45] Catts VS, Catts SV. Apoptosis and schizophrenia: is the tumour suppressor gene, p53, a candidate susceptibility gene?Schizophr Res. 2000; 41:405-15.

[46] Ni X, Trakalo J, Valente J, Azevedo MH, Pato MT, et al. Human p53 tumor suppressor gene (TP53) and schizophrenia: case-control and family studies.NeurosciLett. $2005 ; 388: 173-8$

[47] Chiu HJ, Wang YC, Chen JY, Hong CJ, Tsai SJ. Association study of the p53-gene Pro72Arg polymorphism in schizophrenia.Psychiatry Res. 2001; 105:279-83.

[48] Papiol S, Arias B, Barrantes-Vidal N, Guitart M, Salgado P, et al. Analysis of polymorphisms at the tumor suppressor gene p53 (TP53) in contributing to the risk for schizophrenia and its associated neurocognitive deficits.NeurosciLett. 2004; 363:78-80.

[49] Yang Y, Xiao Z, Chen W, Sang H, Guan Y, et al. Tumor suppressor gene TP53 is genetically associated with schizophrenia in the Chinese population.NeurosciLett. 2004; 369:126-31

[50] Molina V, Papiol S, Sanz J, Rosa A, Arias B, et al. Convergent evidence of the contribution of TP53 genetic variation (Pro72Arg) to metabolic activity and white matter volume in the frontal lobe in schizophrenia patients.Neuroimage. 2011; 56:45-51. 
[51] Lo PK, Chen JY, Tang PP, Lin J, Lin CH, et al. Identification of a mouse thiamine transporter gene as a direct transcriptional target for p53. J Biol Chem. 2001; 276:37186-93

[52] McLure KG, Takagi M, Kastan MB. NAD+ modulates p53 DNA binding specificity and function. Mol Cellular Biol. 2004; 24:9958-67.

[53] Yang Z, Ge J, Yin W, Shen H, Liu H, Guo Y. The expression of p53, MDM2 and Ref1 gene in cultured retina neurons of $\mathrm{SD}$ rats treated with vitamin B1 and/or elevated pressure. Yan KeXueBao. 2004; 20:259-63. [Article in Chinese]

[54] Wong CT, Tsoi WF, Saha N. Acute phase proteins in male Chinese schizophrenic patients in Singapore.Schizophr Res. 1996; 22:165-71.

[55] Shcherbakova IV, Kozlovskaia GV, Kalinina MA, Kliushnik TP. [A state of innate and adaptive immunity in children with schizophrenia and in the high-risk group for the disease].ZhNevrolPsikhiatrIm S SKorsakova. 2005; 105:459. [Article in Russian]

[56] Zozulia SA, Siriachenko TM, Kaleda VG, Dupin AM, Omel'chenko MA, et al. [The state of the immune system in endogenous mental diseases with pronounced affective disorders].ZhNevrolPsikhiatrIm S SKorsakova. 2011; 111:63-7. [Article in Russian]

[57] Kliushnik TP, Kalinina MA, Sarmanova ZV, Otman IN, Kozlovskaia GV. [Dynamics of immunological and clinical parameters in the treatment of childhood schizophrenia].ZhNevrolPsikhiatrIm S SKorsakova. 2009; 109:46-9. [Article in Russian]

[58] Rudduck C, Franzén G, Lindström L. Alpha 1-antitrypsin types in schizophrenia.Hum Hered. 1985; 35:193-5.

[59] Schmechel DE. Art, alpha-1-antitrypsin polymorphisms and intense creative energy: blessing or curse?Neurotoxicology. 2007; 28:899-914.

[60] Imagawa M. Low erythrocyte coenzyme Q10 level in schizophrenic patients.Low erythrocyte coenzyme Q10 level in schizophrenic patients.Jpn J Psychiatry Neurol. 1989; 43:143-5.

[61] Diplock AT, Bunyan J, Green J, Edwin EE. Studies on vitamin E. 7. The effect of thiamine, riboflavin and pantothetic acid on ubiquinone and ubichromenol in the rat. Biochem J. 1961; 79:105-8.

[62] Yang SD, Yu JS, Lee TT, Yang CC, Ni MH, Yang YY. Dysfunction of protein kinase FA/GSK-3 alpha in lymphocytes of patients with schizophrenic disorder. J Cell Biochem. 1995; 59:108-16.

[63] Nadri C, Dean B, Scarr E, Agam G. GSK-3 parameters in postmortem frontal cortex and hippocampus of schizophrenic patients. Schizophr Res. 2004; 71:377-82.

[64] Kozlovsky N, Regenold WT, Levine J, Rapoport A, Belmaker RH, Agam G. GSK-3beta in cerebrospinal fluid of schizophrenia patients. J Neural Transm. 2004; 111:1093-8.

[65] Nadri C, Lipska BK, Kozlovsky N, Weinberger DR, Belmaker RH, Agam G. Glycogen synthasekinase (GSK)3 beta levels and activity in a neurodevelopmental rat model of schizophrenia. Brain Res Dev Brain Res. 2003; 141:33-7.
[66] Beasley C, Cotter D, Khan N, Pollard C, Sheppard P, et al. Glycogen synthasekinase-3beta immunoreactivity is reduced in the prefrontal cortex in schizophrenia.NeurosciLett. 2001; $302: 117-20$

[67] Kozlovsky N, Belmaker RH, Agam G. Low GSK-3 activity in frontal cortex of schizophrenic patients.Schizophr Res. $2001 ; 52: 101-5$.

[68] Zhao J, Sun X, Yu Z, Pan X, Gu F, et al. Exposure to pyrimidine increases beta-amyloid accumulation, Tau hyperphosphorylation, and glycogen synthetase kinase-3 activity in the brain. Neurotox Res. 2010; 19:575-83.

[69] Pan X, Gong N, Zhao J, Yu Z, Gu F, et al. Powerful beneficial effects of benfotiamine on cognitive impairment and betaamyloid deposition in amyloid precursor protein/presenilin-1 transgenic mice. Brain. 2010; 133:1342-51.

[70] Bierhaus A, Humpert PM, Morcos M, Wendt T, Chavakis T, et al. Understanding RAGE, the receptor for advanced glycation end products. J Mol Med (Berl). 2005; 83:876-86.

[71] Arai M, Yuzawa H, Nohara I, Ohnishi T, Obata N, et al. Enhanced carbonyl stress in a subpopulation of schizophrenia.Arch Gen Psychiatry. 2010; 67:589-97.

[72] Itokawa M, Arai M, Ichikawa T, Miyashita M, Okazaki Y. [Studies on pathophysiology of schizophrenia with a rare variant as a clue].Brain Nerve. 2011; 63:223-31. [Article in Japanese]

[73] Toyosima M, Maekawa M, Toyota T, Iwayama Y, Arai M, et al. Schizophrenia with the 22q11.2 deletion and additional genetic defects: case history.Br J Psychiatry. 2011; 199:245-6.

[74] Itokawa M, Arai M, Ichikawa T, Miyashita M, Yoshikawa T, et al. [Molecular pathophysiology of schizophrenia and preventive strategy in pubertal period]. SeishinShinkeigakuZasshi. 2011; 113(7):672-8. [Article in Japanese]

[75] Steiner J, Walter M, Wunderlich MT, Bernstein HG, Panteli $\mathrm{B}$, et al. A new pathophysiological aspect of S100B in schizophrenia: potential regulation of S100B by its scavenger soluble RAGE.Biol Psychiatry. 2009; 65:1107-10.

[76] Suchankova P, Klang J, Cavanna C, Holm G, Nilsson S, et al. Is the Gly82Ser polymorphism in the RAGE gene relevant to schizophrenia and the personality trait psychoticism?J Psychiatry Neurosci. 2012; 37:122-8.

[77] Karachalias N, Babaei-Jadidi R, Rabbani N,Thornalley PJ. Increased protein damage in renal glomeruli, retina, nerve, plasma and urine and its prevention by thiamine and benfotiamine therapy in a rat model of diabetes. Diabetologia. 2010; 53:1506-16.

[78] Karachalias N, Babaei-Jadidi R, Kupich C, Ahmed N, Thornalley PJ. High-dose thiamine therapy counters dyslipidemia and advanced glycation of plasma protein in streptozotocin-induced diabetic rats. Ann N Y Acad Sci. 2005; 1043:777-83.

[79] Stirban A, Negrean M, Stratmann B, Gawlowski T, Horstmann $\mathrm{T}$, et al. Benfotiamine prevents macro- and microvascular endothelial dysfunction and oxidative stress following a meal rich in advancedglycation end products in individuals with type 2 diabetes.Diabetes Care. 2006; 29:2064-71 
[80] Kihm LP, Müller-Krebs S, Klein J, Ehrlich G, Mertes L, et al. Benfotiamine protects against peritoneal and kidney damage in peritoneal dialysis.J Am SocNephrol. 2011; 22:914-26.

[81] Polizzi FC, Andican G, Cetin E, Civelek S, Yumuk V, Burçak G. Increased DNA-Glycation in Type 2 Diabetic Patients: The Effect of Thiamine and Pyridoxine Therapy.ExpClinEndocrinol Diabetes. 2012; 120:329-34.

[82] Chang SH, Chiang SY, Chiu CC, Tsai CC, Tsai HH, et al. Expression of anti-cardiolipin antibodies and inflammatory associated factors in patients with schizophrenia.Psychiatry Res. 2011; 187:341-6.

[83] Ganzinelli S, Borda E, Sterin-Borda L. Autoantibodies from schizophrenia patients induces cerebral cox-1/iNOS mRNA expression with NO/PGE2/MMP-3 production.Int J Neuropsychopharmacol. 2010; 13:293-303.

[84] Rybakowski JK, Skibinska M, Kapelski P, Kaczmarek L, Hauser J. Functional polymorphism of the matrix metalloproteinase-9 (MMP-9) gene in schizophrenia.Schizophr Res. 2009; 109:90-3.

[85] Beauchesne E, Desjardins P, Hazell AS, Butterworth RF. Altered expression of tight junction proteins and matrix metalloproteinases in thiamine-deficient mouse brain.Neurochem Int. 2009; 55:275-81.

[86] Kohda Y, Shirakawa H, Yamane K, Otsuka K, Kono T, et al. Prevention of incipient diabetic cardiomyopathy by highdose thiamine. J Toxicol Sci. 2008; 33:459-72.

[87] Tarallo S, Beltramo E, Berrone E, Dentelli P, Porta M. Effects of high glucose and thiamine on the balance between matrix metalloproteinases and their tissue inhibitors in vascular cells. ActaDiabetol. 2010; 47:105-11.

[88] Kobayashi T, Notoya K, Nakamura A, Akimoto K. Fursultiamine, a vitamin B1 derivative, enhances chondroprotective effects of glucosamine hydrochloride and chondroitin sulfate in rabbit experimental osteoarthritis. Inflamm Res. 2005; 54:249-55.

[89] Hipskind RA, Bilbe G.MAP kinase signaling cascades and gene expression in osteoblasts.Front Biosci. 1998; 3:d804-16.

[90] Kyosseva SV, Elbein AD, Griffin WS, Mrak RE, Lyon M, Karson CN. Mitogen-activated protein kinases in schizophrenia. Biol Psychiatry. 1999; 46:689-96.

[91] Yadav UC, Kalariya NM, Srivastava SK, Ramana KV. Protective role of benfotiamine, a fat-soluble vitamin B1 analogue, in lipopolysaccharide-induced cytotoxic signals in murine macrophages.Free RadicBiol Med. 2010; 48:1423-34.

[92] Akbarian S, Bunney WE Jr, Potkin SG, Wigal SB, Hagman $\mathrm{JO}$, et al. Altered distribution of nicotinamide-adenine dinucleotide phosphate-diaphorase cells in frontal lobe of schizophrenics implies disturbances of cortical development.Arch Gen Psychiatry. 1993;50:169-77.

[93] Akbarian S, Viñuela A, Kim JJ, Potkin SG, Bunney WE Jr, Jones EG. Distorted distribution of nicotinamide-adenine dinucleotide phosphate-diaphorase neurons in temporal lobe of schizophrenics implies anomalous cortical development.Arch Gen Psychiatry. 1993; 50:178-87.

[94] Martins-de-Souza D, Maccarrone G, Wobrock T, Zerr I, Gormanns P, et al. Proteome analysis of the thalamus and cerebrospinal fluid reveals glycolysis dysfunction and potential biomarkers candidates for schizophrenia.J Psychiatr Res. 2010; 44:1176-89.

[95] Pae CU, Yu HS, Kim JJ, Lee CU, Lee SJ, et al. Quinone oxidoreductase (NQO1) gene polymorphism $(609 \mathrm{C} / \mathrm{T})$ may be associated with tardive dyskinesia, but not with the development of schizophrenia.Int J Neuropsychopharmacol. 2004; 7:495-500

[96] Behrens MM, Sejnowski TJ. Does schizophrenia arise from oxidative dysregulation of parvalbumin-interneurons in the developing cortex? Neuropharmacology. 2009; 57:193-200.

[97] Shangari N, Mehta R, O'brien PJ. Hepatocyte susceptibility to glyoxal is dependent on cell thiamin content. ChemBiol Interact. 2007; 165:146-54.

[98] Galdhar NR, Pawar SS. Hepatic drug metabolism and lipid peroxidation in thiamine deficient rats.Int J VitamNutr Res. 1976 ; 46:14-23.

[99] Fraser DA, Hessvik NP, Nikolić N, Aas V, Hanssen KF, et al Benfotiamine increases glucose oxidation and downregulates NADPH oxidase 4 expression in cultured human myotubes exposed to both normal and high glucose concentrations. Genes Nutr. 2012; 7:459-69.

[100] Grosse W 3rd, Wade AE. The effect of thiamine consumption on liver microsomal drug-metabolizing pathways. J PharmacolExpTher. 1971; 176:758-65.

[101] Tassoni D, Kaur G, Weisinger RS, Sinclair AJ. The role of eicosanoids in the brain. Asia Pac J ClinNutr. 2008;17 Suppl $1: 220-8$.

[102] Martínez-Gras I, Pérez-Nievas BG, García-Bueno B, Madrigal JL, Andrés-Esteban E, et al. The antiinflammatory prostaglandin $15 \mathrm{~d}-\mathrm{PGJ} 2$ and its nuclear receptor PPARgamma are decreased in schizophrenia. Schizophr Res. 2011; 128:15-22.

[103] Tang B, Capitao C, Dean B, Thomas EA. Differential ageand disease-related effects on the expression of genes related to the arachidonic acid signaling pathway in schizophrenia. Psychiatry Res. 2012; 196:201-6.

[104] Müller N, Riedel M, Scheppach C, Brandstätter B, Sokullu $\mathrm{S}$, et al. Beneficial antipsychotic effects of celecoxib add-on therapy compared to risperidone alone in schizophrenia.Am J Psychiatry. 2002; 159:1029-34.

[105] Akhondzadeh S, Tabatabaee M, Amini H, AhmadiAbhari SA, et al. Celecoxib as adjunctive therapy in schizophrenia: a double-blind, randomized and placebo-controlled trial.Schizophr Res. 2007; 90:179-85.

[106] Müller N, Krause D, Dehning S, Musil R, Schennach-Wolff $\mathrm{R}$, et al. Celecoxib treatment in an early stage of schizophrenia: results of a randomized, double-blind, placebo-controlled trial of celecoxib augmentation of amisulpride treatment. Schizophr Res. 2010; 121:118-24.

[107] Gu B, Desjardins P, Butterworth RF. Selective increase of neuronal cyclooxygenase-2 (COX-2) expression in vulvenerable brain regions of rats with experimental Wernicke's encephalopathy: effect of numesulide. Metab Brain Dis. 2008; 23:175-87.

[108] Liu S, Stromberg A, Tai HH, Moscow JA. Thiamine transporter gene expression and exogenous thiamine 
modulate the expression of genes involved in drug and prostaglandin metabolism in breast cancer cells. Mol Cancer Res. 2004; 2:477-87.

[109] Tai HH, Tong M, Ding Y. 15-hydroxyprostaglandin dehydrogenase (15-PGDH) and lung cancer.Prostaglandins Other Lipid Mediat. 2007; 83:203-8.

[110] Yaday UC, Subramanyam S, Ramana KV. Prevention of endotoxin-induced uveitis in rats by benfotiamine, a lipophilic analogue of vitamin B1. Invest Ophthalmol Vis Sci. 2009; 50:2276-82.

[111] Akyol O, Herken H, Uz E, Fadillioğlu E, Unal S, Söğü S, et al. The indices of endogenous oxidative and antioxidative processes in plasma from schizophrenic patients. The possible role of oxidant/antioxidant imbalance.ProgNeuropsychopharmacolBiol Psychiatry. 2002; 26:995-1005.

[112] Dietrich-Muszalska A, Kontek B. Lipid peroxidation in patients with schizophrenia.Psychiatry ClinNeurosci. 2010; $64: 469-75$

[113] Herken H, Uz E, Ozyurt H, Söğüt S, Virit O, Akyol O. Evidence that the activities of erythrocyte free radical scavenging enzymes and the products of lipid peroxidation are increased in different forms of schizophrenia.Mol Psychiatry. 2001;6:66-73.

[114] Khan MM, Evans DR, Gunna V, Scheffer RE, Parikh VV, Mahadik SP. Reduced erythrocyte membrane essential fatty acids and increased lipid peroxides in schizophrenia at the never-medicated first-episode of psychosis and after years of treatment with antipsychotics.Schizophr Res. 2002; 58:1-10.

[115] Wu Z, Zhang XY, Wang H, Tang W, Xia Y, et al. Elevated plasma superoxide dismutase in first-episode and drug naive patients with schizophrenia: inverse association with positive symptoms.ProgNeuropsychopharmacolBiol Psychiatry. 2012; 36:34-8.

[116] Kunz M, Gama CS, Andreazza AC, Salvador M, Ceresér KM, et al. Elevated serum superoxide dismutase and thiobarbituric acid reactive substances in different phases of bipolar disorder and in schizophrenia. ProgNeuropsychopharmacolBiol Psychiatry. 2008; 32:1677-81.

[117] Akyol O, Yanik M, Elyas H, Namli M, Canatan H, et al. Association between Ala-9Val polymorphism of Mn-SOD gene and schizophrenia. ProgNeuropsychopharmacolBiol Psychiatry. 2005; 29:123-31.

[118] Padurariu M, Ciobica A, Dobrin I, Stefanescu C. Evaluation of antioxidant enzymes activities and lipid peroxidation in schizophrenic patients treated with typical and atypical antipsychotics. NeurosciLett. 2010; 479:317-20.

[119] Calingasan NY, Chun WJ, Park LC, Gibson GE. Oxidative stress is associated with region-specific neuronal death during thiamine deficiency. J NeuropatholExp Neurol. 1999; 58:946-958.

[120] Gioda CR, de Oliveira Barreto T, Prímola-Gomes TN, de Lima DC, Campos PP, et al. Cardiac oxidative stress is involved in heart failure induced by thiamine deprivation in rats.Am J Physiol Heart Circ Physiol. 2010;298:H2039-45.
[121] Lukienko PI, Mel'nichenko NG, Zverinskii IV, Zabrodskaya SV. Antioxidant properties of thiamine. Bull ExpBiol Med. 2000; 130:874-6.

[122] Portari GV, Marchini JS, Vannucchi H, Jordao AA. Antioxidant effect of thiamine on acutely alcoholized rats and lack of efficacy using thiamine or glucose to reduce blood alcohol content. Basic ClinPharmacolToxicol. 2008; 103:482-6.

[123] Jung IL, Kim IG. Thiamine protects against paraquatinduced damage: scavenging activity of reactive oxygen species. Environ ToxicolPharmacol. 2003; 15:19-26.

[124] Park DJ, West AR. Regulation of striatal nitric oxide synthesis by local dopamine and glutamate interactions.J Neurochem. 2009; 111:1457-65.

[125] West AR, Galloway MP, Grace AA. Regulation of striatal dopamine neurotransmission by nitric oxide: effector pathways and signaling mechanisms.Synapse. 2002; 44:22745.

[126] Karson CN, Griffin WS, Mrak RE, Husain M, Dawson TM, et al. Nitric oxide synthase (NOS) in schizophrenia: increases in cerebellar vermis.MolChemNeuropathol. 1996; 27:275-84.

[127] Silberberg G, Ben-Shachar D, Navon R. Genetic analysis of nitric oxide synthase 1 variants in schizophrenia and bipolar disorder.Am J Med Genet B Neuropsychiatr Genet. 2010; 153B:1318-28.

[128] Reif A, Schecklmann M, Eirich E, Jacob CP, Jarczok TA, et al. A functional promoter polymorphism of neuronal nitric oxide synthase moderates prefrontal functioning in schizophrenia. Int J Neuropsychopharmacol. 2011;14:887-97

[129] Rose EJ, Greene C, Kelly S, Morris DW, Robertson IH, et al. The NOS1 variant rs6490121 is associated with variation in prefrontal function and grey matter density in healthy individuals.Neuroimage. 2012; 60:614-22.

[130] Herken H, Uz E, Ozyurt H, Akyol O. Red blood cell nitric oxide levels in patients with schizophrenia. Schizophr Res. 2001; 52:289-90.

[131] Raffa M, Atig F, Mhalla A, Kerkeni A, Mechri A. Decreased glutathione levels and impaired antioxidant enzyme activities in drug-naive first-episode schizophrenic patients.BMC Psychiatry. 2011; 11:124.

[132] Cabungcal JH, Nicolas D, Kraftsik R, Cuénod M, Do KQ, Hornung JP. Glutathione deficit during development induces anomalies in the rat anterior cingulate GABAergic neurons: Relevance to schizophrenia. Neurobiol Dis. 2006;22:624-37

[133] Gravina P, Spoletini I, Masini S, Valentini A, Vanni D, et al. Genetic polymorphisms of glutathione S-transferases GSTM1, GSTT1, GSTP1 and GSTA1 as risk factors for schizophrenia. Psychiatry Res. 2011; 187:454-6.

[134] Lương KVQ, Nguyễn LTH. The impact of thiamine treatment on generalized anxietydisorder. Int J Clin Med. $2011 ; 2: 439-43$. 